\title{
Pueblo gitano y consumo mediático informativo: ¿audiencia crítica y activa?
}

Romani people and informational media consumption: critical and active audience?

\author{
Marques-Gonçalves, Gabriela \\ Universitat Autònoma de Barcelona (UAB) \\ gabimarques@pm.me
}

Forma de citar este artículo:

Marques-Gonçalves, G. (2020). "Pueblo gitano y consumo mediático informativo: ¿audiencia crítica y activa?", RAEIC, Revista de la Asociación Española de Investigación de la Comunicación, vol. 7, núm. 13, 164-184

https://doi.org/10.24137/raeic.7.13.8

\section{Resumen:}

Este artículo tiene como objetivo presentar una discusión sobre el carácter crítico y activo de la población gitana en cuanto audiencia. Para ello, se hará una revisión teórica sobre los estudios de audiencia que interpretan el público desde una perspectiva de pasividad o de agencia y también aquellos que debaten las particularidades del consumo mediático por las minorías. En los resultados, se presentarán las reflexiones de miembros de este colectivo sobre cómo su pueblo es representado en los contenidos informativos de los medios de comunicación de España. La metodología utilizada ha sido 
las entrevistas semiestructuradas con 20 gitanos y gitanas de la provincia de Barcelona entre los años 2017 y 2019. Como conclusión, destacamos la capacidad crítica de los interlocutores en evaluar lo que se está produciendo sobre ellos en los medios tradicionales y también el uso del entorno digital en la interacción y producción de contenidos propios.

Palabras clave: audiencia, pueblo gitano, Barcelona, Internet, representación.

\section{Abstract:}

This paper aims to present a discussion about the critical and active character of the Romani population as audience. Therefore, a theoretical revision will be done, examining audience studies that interpret the public from a perspective of passivity or agency. We will also discuss those studies that debate the particularities of media consumption by minorities. In the results, the reflexions by the interviewees will be presented, discussing how their community is represented in news reports in Spanish media. The methodology consisted of semi-structured interviews with 20 Romani women and men from Barcelona (Catalonia) between 2017 and 2019. To conclude, we highlight the critical capacity of the interlocutors in evaluating what is being produced about them in traditional media and also the use of digital environments to interact and produce their own contents.

Keywords: audience, Romani people, Barcelona, Internet, representation.

\section{INTRODUCCIÓN}

Según Willem (2010), el estudio de los medios de comunicación ha tendido hacia dos enfoques bien diferenciados: el texto y la audiencia. Tales perspectivas tienen cierta semejanza con la oposición entre estructura y agencia en el campo sociológico. No obstante, estas divisiones y enfoques son más bien modelos esquemáticos de estudios; y no, una división rigurosa, ya que estos elementos están en constante interacción. Por ello, resulta todo un reto encontrar un término intermedio entre una postura teórica 
que no conceda un poder total al mensaje con un sentido ya pre generado y otra que asigne a la audiencia completa autonomía y capacidad crítica frente a los contenidos. Como destaca Cogo, Gutiérrez y Huertas (2008), ser audiencia requiere la activación de mecanismos de atención, comprensión e interpretación, lo que le da la "capacidad de reinterpretar los sentidos otorgados por los medios de comunicación e, igualmente, de crear estrategias de acceso y uso de las tecnologías disponibles en su entorno cotidiano" (pp. 10-11). Sin embargo, en lo que se refiere a los medios de comunicación de masas, esta activación se da desde procesos comunicativos asimétricos y/o unidireccionales.

Dicho esto, este artículo tiene como objetivo presentar una discusión sobre el carácter crítico y activo de la población gitana en cuanto audiencia, sin dejar de considerar que estamos trabajando con un grupo étnico que es la minoría más numerosa del continente europeo. Según informes de la Década por la Inclusión de los Gitanos, en 2015 la población gitana seguía enfrentándose en su día a día a problemas que demostraban la falta de garantía de sus derechos fundamentales. En España, según declaración ${ }^{1}$ del Relator Especial de las Naciones Unidas sobre cuestiones relacionadas con las minorías, la población gitana es una minoría que sigue entre las más marginadas y vulnerables del país y reconoció que el Antigitanismo continúa estando "muy extendido y profundamente arraigado en los comportamientos sociales y culturales y en las prácticas institucionales" (2019, no paginado). Además, entendemos que la marginación histórica, social y económica que ha sufrido la comunidad gitana en el país queda reflejada en su escasa presencia en la oferta mediática (Oleaque, 2014; Tortajada, 2009).

Así, para realizar el debate que se propone aquí, presentaremos una revisión de literatura sobre los estudios de comunicación que abordan la audiencia desde su carácter pasivo o activo y también sobre el consumo mediático desde la perspectiva de las minorías para comprender cómo ello afecta el proceso de recepción de contenidos. Es importante destacar que los conceptos relacionados con el consumo mediático van cambiando y acompañando las mudanzas del contexto social y de las investigaciones producidas sobre el tema. Público, receptor o audiencia son algunas de las palabras

\footnotetext{
${ }^{1}$ Recuperado el 12 de mayo de 2019 de https://www.ohchr.org/SP/NewsEvents/Pages/DisplayNews.aspx?NewsID=24112\&LangID=S
} 
utilizadas en el debate sobre el consumo mediático que se desarrolla desde diferentes puntos de partida.

Para la realización de este trabajo, hemos utilizados herramientas metodológicas cualitativas como la observación participante y entrevistas semiestructuradas con 20 gitanos y gitanas, mayores de 18 años, de la provincia de Barcelona entre los años de 2017 y 2019. En los resultados, se presentarán las reflexiones de los miembros de este colectivo sobre cómo su pueblo es representado en los contenidos informativos de los medios de comunicación de España. Para concluir, destacamos la capacidad crítica de los interlocutores en evaluar lo que se está produciendo sobre ellos en los medios tradicionales y también el uso del entorno digital en la interacción y producción de contenidos propios.

\section{REVISIÓN DE LITERATURA}

El nivel de autonomía del público para la interpretación de los mensajes en los procesos comunicativos ha sido analizado desde diferentes perspectivas en los estudios de comunicación. En el campo de las ciencias sociales norteamericanas, donde se desarrollaron los análisis centrados en los individuos o en grupos de individuos, se empezó a considerar la influencia de los contextos culturales que rodean la audiencia desde muy temprano (Wolf, 1995). Así, a inicios del siglo XX, se llegó a indicar que estos, por ejemplo, podían provocar que los mensajes persuasivos no llegaran con la misma efectividad. Se abandonó la preocupación por cómo generar determinados efectos en la audiencia para pasar a pensar sobre cómo condicionar la recepción de los mensajes, reduciendo los ruidos durante su emisión desde una perspectiva más funcional. El interés y la percepción de los mensajes son vistos como el resultado de experiencias propias marcadas por determinados contextos. Desde las perspectivas psicológicas, el público es capaz de, conscientemente, seleccionar, evaluar y estructurar los contenidos a partir de los significados que estos tienen para él.

En los años 1960 y 1970, la preocupación de muchos intelectuales pasa a ser la amenaza de la homogeneización de la cultura de masas (Sodré, 2002). En este contexto, se cree que la cultura del consumo desarrolla la pasividad en los sujetos, que dejan de actuar y 
crear. La creación y la transformación siguen relegadas a la élite, mientras el resto de la población solo consume. Consume, incluso, la idea de que puede crear (Certeau, 1995). Para el historiador francés, "la cultura es el campo de un neocolonialismo"2 (1995, p.234). La flexibilidad de la cultura es explorada por la rigidez del mercado, tornando "lucrativa la fabricación de significados"3. Se vende el acceso a los bienes materiales, teniendo la información un papel clave en ese proceso, ya que los valores de estos bienes ganan sentido a partir del momento en que pueden simbolizar identidades y estilos de vida de sus consumidores.

Desde otra perspectiva, con los Estudios Culturales, gana fuerza la idea de que la audiencia es activa, además del uso de un abordaje cualitativo en las investigaciones. El modelo de codificación y decodificación de Stuart Hall, por ejemplo, buscó un equilibrio entre la teoría de los efectos y la de usos y gratificaciones, considerando tanto el poder de los medios de comunicación para definir agendas, como el carácter activo del receptor para producir sus propios significados (Willem, 2010). Los sujetos pasan a ser vistos como capaces de explicar sus experiencias como audiencia y esta línea de investigación se preocupa por saber "cómo se sumergen los medios en la vida cotidiana y cómo éstos son utilizados como fuente de conocimiento material y simbólico" (Huertas, 2013, p.126). Ya los estudios de recepción del abordaje teórico-metodológico sociodiscursivo destacan los significados y discursos que los receptores construyen a partir de los contenidos mediáticos, y los interpreta a partir de sus cualidades psicológicas y contextos sociales, identificando las resistencias que tienen lugar en este proceso. Aunque ya no les interesa tanto saber el significado real del mensaje, este sigue en el centro de atención, ya que buscan saber "qué significados se recogen, cuáles predominan y cuáles se suprimen" en el proceso de recepción (Huertas, 2013, p.128).

Con los avances tecnológicos, el desarrollo de los ambientes digitales y virtuales es visto como una manera de proporcionar mayor participación del público. Según Murray (2003), "la tradición posmoderna del hipertexto celebra el texto indeterminado como una liberación de la tiranía del autor y una afirmación de la libertad interpretativa del

\footnotetext{
2 Traducción libre del texto original en portugués.

${ }^{3}$ Traducción libre del texto original en portugués.
} 
lector"4 $^{\prime \prime}$ (p.132). La naturaleza participativa del ambiente digital propiciaría la creación de narrativas más cercanas a las experiencias de la vida misma, lo que posibilitaría "incrementar nuestro repertorio de acciones, ampliar los modelos por los que aprehendemos e interpretamos el mundo, transformar los modos con que pensamos unos en los otros y cómo nos tratamos mutuamente" ${ }^{5}$ (Murray, 2003, p.10). Para la autora, lo que difiere la acción del público delante de los diferentes medios es la conciencia de su participación.

... leer $y$ ver no son de ninguna forma experiencias pasivas, pero requieren nuestra participación para construir la historia de un modo activo. Persisten diferencias, no obstante, entre esa actividad cognitiva y emocional y sus acciones externas que realizamos en un juego o en una narrativa electrónica. Quizás la diferencia más importante sea el hecho de que, en esa última, somos conscientes de nuestra actividad, lo que altera nuestra relación con la historia. ${ }^{6}$ (Murray, 2003, p.150)

Sin embargo, es importante destacar que toda esta autonomía proporcionada a la audiencia se da dentro de estructuras predefinidas por los productores, las cuales modelan la participación del público teniendo en cuenta las reglas de funcionamiento del sistema. Así, se podría preguntar si no resultarán los productores más beneficiados por el carácter interactivo de las nuevas tecnologías que el propio público. Ello porque los primeros pasan a tener más libertad en los procesos de creación de nuevos formatos, mientras que el público puede distraerse con la capacidad enciclopédica de los sistemas llegando al punto de no cuestionar "los motivos por los que las cosas funcionan de una determinada manera y el porqué de que seamos invitados a asumir tal rol y no otro diferente" ${ }^{\prime 7}$ en este proceso interactivo (Murray, 2003, p.93).

Esto nos sugiere que, aunque los niveles de acción del público puedan aumentar con las nuevas posibilidades ofrecidas por el desarrollo tecnológico, el proceso de codificación

\footnotetext{
${ }^{4}$ Traducción libre del texto original en portugués.

${ }^{5}$ Traducción libre del texto original en portugués.

6 Traducción libre del texto original en portugués.

${ }^{7}$ Traducción libre del texto original en portugués.
} 
de los mensajes sigue siendo más sofisticado que el de decodificación. Productores y consumidores no tienen el mismo poder. Así, al mismo tiempo que hay una mayor diversidad de elección o más aperturas para intervenciones de culturas e ideas diferentes, hay también una mayor vigilancia y control social (Kellner, 2001). Sin embargo, considerar que no haya ninguna interferencia del receptor en la interpretación de los mensajes es seguir invisibilizando que el público tiene repertorios ideológicos y culturales propios. Al mismo tiempo, asumir que los productores de contenido tienen total control sobre el mensaje es ignorar los contextos en los cuales ellos también están insertos, sean personales, sociales o del entorno profesional. Como nos recuerda Tortajada (2009), aunque los mensajes tengan un significado preferente, ello no es determinante, sino dominante.

En este sentido, es importante destacar las particularidades de consumo de acuerdo con las situaciones socioeconómicas de la audiencia, como es el caso de las minorías. Estos grupos son resultado de procesos históricos en los que sus rasgos identitarios son enfatizados para justificar su exclusión de los procesos socioeconómicos en determinadas sociedades. Por ello, para poder comprender el rol de estos grupos sociales en relación al consumo mediático, cabe tener en cuenta que el contexto socioeconómico debe ser considerado desde una perspectiva histórica. Además, se hace necesario destacar la importancia de los medios de comunicación tanto en la construcción de los debates públicos como a la hora de definir los espacios que se dejan a los grupos minoritarios en estos espacios de debate.

Como destaca Willem (2010, p.31), en lugar de invitar a la audiencia a cuestionar los estereotipos sobre las minorías, los medios de comunicación generan mensajes hegemónicos sobre ellos. Los mass media llevan mucho tiempo presentando los grupos étnicos minoritarios desde la mirada de la sociedad mayoritaria, reforzando y construyendo perspectivas discriminatorias sobre estas comunidades (Ross y Playdon, 2001). Una de las consecuencias de dicho proceso es la interiorización por parte de las propias minorías de esas imágenes que hablan de ellas, reproduciendo, así, los estereotipos difundidos o presentando una baja autoestima (Willem, 2010; Ross, 2001). Obviamente, la interiorización de imágenes producidas por los medios de comunicación 
depende de diversos aspectos y de los roles que tienen estos sujetos desde diferentes lugares como el sexo, el género, la clase social, la escolaridad, la edad, etc.

Como apuntan Ross y Playdon (2001), "patrones de visionado entre audiencias de minorías étnicas necesitan ser vistos dentro de un marco multipolar más complejo en el cual etnicidad, siendo desde luego un factor, no es siempre una fuerza dominante" ${ }^{8}$ (pp. XVII-XVIII). A su vez, Tsagarousianou (2001) destaca que las comunidades étnicas presentan un consumo mediático extremadamente complejo y que su pertenencia étnica debe ser vista como un proceso y no como una esencia. Así, diversos factores contribuyen a que existan diferentes niveles de resistencia a los intentos de estereotipación de los grupos minoritarios. Tal resistencia se da, por ejemplo, con la producción de imágenes positivas, sea a través de medios de comunicación alternativos, sea por el trabajo desarrollado por algunos profesionales de la comunicación (Willem, 2010). Según Ross y Playdon (2001), "audiencias pertenecientes a minorías étnicas demuestran destacable resiliencia, recursos y habilidad en sus prácticas de consumo, articulando discursos de derechos culturales relacionados con su especificidad étnica y diaspórica, pero también reivindicando inclusión en el 'mainstream'”99 (p. XIV).

Las minorías en cuanto audiencia se confrontan muchas veces o con la subrepresentación de sus grupos identitarios y culturales en los medios de comunicación o con una representación basada en estereotipos (Willem, 2010). Ello porque los productos mediáticos y culturales están insertos dentro de supuestos culturales y prejuicios compartidos por sus productores, que tienen en general experiencias culturales muy similares, lo que refuerza normas culturales y comportamientos, impactando en la manera como la sociedad mayoritaria se relaciona con las minorías en su cotidiano (Ross y Playdon, 2001).

Ross (2001) explica que, al compartir características particulares, las minorías étnicas en cuanto audiencia capturan no solamente el sentido del "nosotros" sino también del "yo", al mostrar visiones particulares sobre términos comunes de discusión. Ello

\footnotetext{
8 Traducción libre del texto original en inglés.

${ }^{9}$ Traducción libre del texto original en inglés.
} 
permite, por lo tanto, hablar también de múltiples y diversas identificaciones dentro de un mismo grupo. Para Ross y Playdon (2001), "audiencias minoritarias no quieren favores especiales en términos de representación, sino que más bien les gustaría ver sus muchos y diversos selves y sus diferentes vidas representadas con más equilibrio"10 (p.XIV).

\section{METODOLOGÍA}

Este artículo forma parte de un trabajo más amplio donde hemos extraído los datos para las reflexiones realizadas aquí. Las informaciones que se presentarán próximamente son resultado de una pesquisa cualitativa cuyas herramientas metodológicas incluyen la observación participante en la etapa exploratoria que posibilitó el contacto con los futuros interlocutores y la realización de entrevistas semiestructuradas. Estas últimas fueron realizadas entre los años de 2017 y 2019 con 10 gitanos y 10 gitanas, entre 18 y 47 años, residentes en la provincia de Barcelona. Las entrevistas duraron una media de 40 minutos, siendo la más larga de una hora y 13 minutos y la más corta de 17 minutos.

Para realizar las entrevistas se buscó crear un ambiente de diálogo distendido, facilitado en aquellos casos que la investigadora conocía previamente a la persona. Se intentó hacer entrevistas que tuvieran como cualidades "la flexibilidad de permitir al informante definir los términos de la respuesta y al entrevistador ajustar libremente las preguntas" $^{11}$ (Barros y Duarte, 2008, p.62). Este es un trabajo cualitativo y, por tanto, no busca una representatividad estadística del universo gitano de Barcelona, por lo que el resultado estará relacionado "a la significación y a la capacidad que las fuentes tienen de dar informaciones fiables y relevantes sobre el tema de la investigación"12 (p.68) siempre relacionándolas con su mundo simbólico y social.

Por ello, este trabajo consistió en buscar y registrar los discursos, argumentaciones y experiencias propias de miembros de la comunidad gitana. Para los análisis que se presentan aquí, hemos partido de preguntas referentes al consumo de contenidos

\footnotetext{
${ }^{10}$ Traducción libre del texto original en inglés.

11 Traducción libre del texto original en portugués.

12 Traducción libre del texto original en portugués.
} 
relacionados a la población gitana y de la opinión de la muestra sobre el modo como su comunidad es representada en los medios de comunicación. La sistematización de los datos se dio primeramente con la transcripción literal y completa de todas las entrevistas realizadas con una preocupación por ser lo más fieles posible al discurso de las personas entrevistadas. Se intentó reproducir las expresiones y modos de hablar de la muestra, con el objetivo de valorizar y visibilizar un legado lingüístico producido desde un contexto cultural propio. Las pequeñas modificaciones hechas resultaron simplemente de la adaptación del discurso hablado al escrito para una mejor comprensión del lector de este texto, ya que no se hizo una descripción de lenguajes corporales o demás herramientas propias de una conversación presencial.

La identificación de la muestra se da a través de una numeración creciente de acuerdo con la edad de los entrevistados, siendo el número uno el más joven, y de las letras $\mathrm{H}$ y $\mathrm{M}$ referentes al sexo. Destacamos también que los y las entrevistadas tienen diferentes niveles de escolaridad, desde la primaria hasta el grado superior, y vienen de contextos familiares diversos en lo referente al origen de sus progenitores.

\section{ANÁLISIS}

Aunque enfocaremos aquí en los resultados relacionados a las reflexiones de los y las entrevistadas en lo referente a la representación del Pueblo Gitano en los medios de comunicación, es importante destacar que en dos momentos del trabajo de campo, la crítica a las producciones mediáticas aparecieron también desde un ámbito más general. En un momento en el cual se habla cada vez más de un consumo personalizado, posibilitado especialmente por los contenidos disponibles en internet, una de las entrevistadas apuntó como la televisión tradicional homogeneiza el consumo hacia una programación de poca calidad, calificada por ella de telebasura. Las críticas también aparecen al hablar de la imparcialidad y objetividad de las noticias:

Me gustan los programas, no me gusta tanto a lo mejor los presentadores y las presentadoras. Cuando veo que se posicionan y que no son imparciales ante la noticia, en seguida notas como se están posicionando cuando están entrevistando alguien a nivel político, con un lado o con el otro. Eso no me gusta, 
me gusta tener la información y hagan su función, pero no que se posicionen en ese momento. (E17M)

... en el tema de las noticias también he visto que hay muchas mentiras, a base de que voy creciendo, depende de qué canal pongas o depende de dónde busques la noticia, te sale una cosa u otra, por eso hay veces que de las noticias te puedes creer la mitad de la mitad, sacas tus propias conclusiones. (E5M)

Ya en relación a las noticias relacionadas al Pueblo Gitano, con excepción de un entrevistado, todos los demás las acompañan, sea en los medios de comunicación tradicionales, sea en las redes sociales. En este caso las asociaciones también juegan un rol muy importante ya que facilitan el intercambio de material entre su personal y voluntarios. Además, el movimiento asociativo se construye por medio de redes entre entidades de diferentes partes de España lo que promueve un diálogo constante entre sus miembros.

...yo casualmente estaba viendo La 2 y estaban dando un documental sobre los gitanos y sobre todo pues la educación, que como estaban saliendo chicas de barracas universitarias. Entonces evidentemente tenemos un grupo en clase y lo compartí, les dije chicos mirar la 2 que están dando un documental muy interesante sobre esto. Lo que pasa es que claro no suele haber esta información, un programa específico cada semana o cada mes sobre el Pueblo Gitano y sus costumbres o cómo está evolucionando. Pero sí que me intereso evidentemente cuando hay algo en televisión o en prensa, claro, lo suelo ver o lo suelo leer. (...) tú lo miras porque te interesa como gitana que eres y te interesa saber qué es lo que está pasando en otras comunidades de España que quizás aquí en Cataluña no esté pasando. (E18M)

...formamos parte de este mundillo y en seguida recibes un WhatsApp de alguien que te dice pon la Sexta o pon tal canal que están dando una noticia que ha pasado esto, ha pasado lo otro, están hablando de gitanos. Y si no has tenido el tiempo de verla en ese momento, luego buscas por Google, lo buscas por ahí para 
ver qué ha pasado, qué han dicho y sobre todo cómo han tratado en el medio la noticia. (E17M)

...tenemos un correo que llegan todas las noticias relacionadas con los gitanos en la prensa. ...todo lo que yo puedo, intento sobre todo compartir en redes y darle visibilidad. ...también depende, depende qué cosas porque hay gente también que escribe sobre el Pueblo Gitano y no conoce el Pueblo Gitano, sabes, es como bueno esto aquí sobra... (E12M)

... a través de la Fundación todos los temas relacionados nos vienen o por correo electrónico o entre compañeros, nos llaman desde la sede de Madrid y ahí nos enteramos todos. Si yo me entero de algo por ejemplo de lo que es la comunidad gitana o de algún tema relacionado, pues sí, yo voy a la información pues mira, ha sucedido tal y tal, entonces ya pues investigas más a fundo, en internet, o vas a algún compañero que está desde la central que quizás domina más el tema. (E10M)

Normalmente los suelo encontrar tanto en el Facebook, Instagram o en Twitter. Tengo agregado la gran mayoría de las asociaciones gitanas que hay en España $y$ en Europa, entonces cuando suele aparecer una noticia normalmente las asociaciones gitanas pues suelen retuitearlo o suelen comentar las noticias en un medio de comunicación. (E8H)

Parte de los entrevistados destaca la identificación étnica en las noticias relacionadas con crímenes o violencia, lo que contribuye a la estigmatización de todo el colectivo. Además, detectan que ello no sucede cuando casos parecidos se refieren a la sociedad mayoritaria. Es importante destacar que la identificación étnica es rechazada en manuales o guías para profesionales de la comunicación - cuando este dato no resulta de interés informativo-, pero aun así es percibida por las personas entrevistadas como una práctica habitual. Joan Oleaque (2014) menciona en su tesis doctoral diversos libros de estilo de medios de comunicación españoles a los que añadimos otros ejemplos: el Código Deontológico de la Profesión Periodística, de la Federación de Asociaciones de Periodistas de España (FAPE), de 1993; la Declaración de Principios de la Profesión 
Periodística del Colegio de Periodistas de Cataluña, derivado de su Código Deontológico de 1992; el manual de estilo sobre minorías étnicas del Colegio de Periodistas de Cataluña de 1996; el informe La imatge de les minories ètniques a les televisions de Catalunya del Consejo de Audiovisual de Cataluña, del año 2000; entre otros. De entre las publicaciones más recientes, sobresalen las Recomendaciones para el tratamiento de la comunidad gitana en los medios de comunicación, del 2018, producido por la Federación Nacional de Asociaciones de Mujeres Gitanas (Kamira) ${ }^{13}$.

Me indigno un poco. Porque cuando por ejemplo un hombre asesina una mujer, dicen un hombre ha asesinado una mujer por violencia de género, un hombre. Pero cuando ese hombre es gitano dicen un hombre de etnia gitana ha matado y eso me da mucha rabia. Porque si no, también pueden decir un hombre de etnia paya. También vi una noticia una vez que compartieron en el Facebook que ponía ha muerto tres hombres y un gitano. ¿Qué pasa? ¿Que el gitano no es hombre? Han muerto cuatro hombres. No tres hombres y un gitano. Que eso la estuvimos compartiendo así todos del cole, por el Facebook, porque lo vimos un poco raro. (E15M)

...hubo una iniciativa que hicieron ... que era como una creación de un diario que lo llamaron Payo Today... Y era en plan que ponían las noticias, pero traducidas digamos a lo gitano. Por ejemplo, un payo ha matado a dos payas no sé qué, no sé cuántos. Y era un poco de decir, pues mira como nosotros nos sentimos cada vez que decís pues mira, un gitano tal, es que nos desprecian, nos discriminan. $Y$ los medios de comunicación tienen mucho poder en la sociedad. Entonces si ya refuerzan estas cosas negativas que es que no son ciertas porque no lo son, no todos somos iguales, no se puede clasificar por razas, es por persona, o sea, hay payos malos, payos buenos, pues lo mismo con los gitanos, es exactamente igual. (E10M)

\footnotetext{
${ }^{13}$ Recuperado el 04 de abril de 2019 de https://www.cac.cat/sites/default/files/201811/Recomanacions comunitat gitana ES.pdf
} 
...la mayoría de las noticias suelen ser noticias muy negativas para resaltar algo negativo hacia el Pueblo Gitano y también mencionar el Pueblo Gitano cuando es completamente innecesario, por ejemplo, ... si una persona blanca comete un delito o una persona no sé catalana cometió un delito, se omite, en cambio cuando una persona es gitana comete un delito, pues lo primero que aparece en la noticia es gitano ha hecho este delito. Es una información completamente pues que no es necesaria de poner, no aporta información en esta noticia, en cambio los medios de comunicación sí que lo ponen... (E8H)

...esta semana el fratricida que ha matado a sus hijas en un pueblo, no dicen que es payo, ¿por qué no si es payo?, ¿por qué no lo dices? Es que es importante que lo digas.... Ah, pero si es gitana, ahí sí que hay alarma y todo el pueblo lo lincharía solamente por ser gitano no por haber matado sus hijas. Perdona, el delito es que mate a sus hijas, no que sea gitano. Pero es que parece al revés. (E19H)

En general, los entrevistados demuestran una mirada muy crítica sobre lo que se emite respeto de los gitanos en las noticias, especialmente porque perciben que hay más contenido negativo que positivo en relación a ellos. En opinión de algunos miembros de la muestra, lo que buscan los medios de comunicación es un titular que llame la atención. Una de las entrevistadas usa expresiones como "amarillista" y "sensacionalista" para describir este tipo de periodismo.

...la cultura gitana en los medios de comunicación son para cosas negativas. Cuando mencionan a un gitano no es para decir pues se han graduado tanto por ciento de gitanos o están escolarizados tanto por ciento de gitanos, no, nunca es algo positivo. En cambio, son noticias negativas, pues un hombre gitano ha matado a tal o un hombre gitano ha robado no sé qué. Y eso es lo que veo, quizás los medios de comunicación refuerzan esos estereotipos de connotaciones negativas que hay de los gitanos y que los medios de comunicación empeoran. (E10M)

Una mala imagen, casi siempre. Siempre sacan cosas malas, no van a sacar nunca algo bueno, y se han hecho muchas cosas buenas, pero nunca van a sacar. (E1H) 
En general son sucesos, o es drogas, o es peleas o es este tipo de cosa. Se hace de la nada, hacer como una gran noticia, no tengo nada que contar, pues explico que alguien ha robado en un supermercado. Eso pasa en todos los sitios, pero no es noticia. (E16H)

Por otro lado, se habló también de una ausencia de este colectivo en los medios de comunicación, cuando apuntan la dificultad de encontrar contenidos que les interese sobre su comunidad. Además, enmarcaron la responsabilidad de los periodistas en la reproducción de estereotipos relacionados con la comunidad a la hora de eligir el enfoque del material o también al apuntar la falta de interés de los profesionales en producir y difundir contenidos relacionados con éxitos de la población gitana. Los entrevistados echan la culpa al profesional periodista, no al medio, ni a su línea editorial.

...es que tampoco sale nada, cuando sale en las noticias que salió la información que dijeron que era el día de los gitanos, que era el 8 de abril y sí que pudieron decir, pues menos mal, que es el día internacional de los gitanos y lo dijeron por las noticias y salieron unas cuantas chicas gitanas explicando qué están estudiando, qué están haciendo. Eso es lo único que he visto en la tele verdaderamente y nada, duró 5 minutos, que ha valido la pena. Pero ya está. (E2M)

Si nos vamos a los programas estos que salen es venga el cachondeo y poca cosa más, pero porque no sacan la parte que hay gente estudiando, hay gente que se está formando, hay gente que quiere salir de la situación en la que está. Esto como no vende, no sale. Entonces no lo podemos ver. ... no es culpa de los gitanos, es culpa de los periodistas que no quieren dar esta información al resto de los televidentes para que puedan ver y puedan comparar que el gitano está evolucionando o intenta evolucionar. Me encantaría que hubiese un programa así. (E18M)

...el día 25 de enero estuvo el Goran Bregovic, que es un cantante de Bosnia Herzegovina, de los Balcanes, que no es gitano, pero que ha colaborado y en su orquesta siempre ha tenido algún gitano y tiene gitanos tocando y estuvo aquí en Barcelona ... y entonces le hacen una entrevista, de toda la entrevista que le 
hacen que me la estuve leyendo, hay una pregunta en el que le preguntan acerca de lo maltratada que ha estado la comunidad Romaní en Europa. Entonces él contesta y dice que todos los gitanos de Europa no han robado, no han llegado a la proporción de lo que un banquero ha podido robar en 15 minutos. Entonces claro, en si Bregovic lo hace con toda la buena intención de decir con todo el estereotipo y toda la mochila que pesa sobre la espalda del pueblo Romaní de ladrones, pero si lo comparamos con lo que hace la gente, los políticos, los banqueros, no se puede comparar y tiene menos importancia, se da menos importancia al otro lado. Pero en la noticia, destacan ese titular precisamente, cuando hay como ocho o diez preguntas que le hacen ahora sobre otros temas, incluso de la guerra de los Balcanes (...) pero destacan esa porque conjuga gitanos, robar, entonces claro. Un chico, que no conozco personalmente, pero lo conozco a través del Facebook, es un chico también activista y tal, critica a Goran Bregovic por su comentario. A mi me suscita la duda de ces culpable Goran Bregovic por su comentario o lo es el periodista que ha hecho la entrevista? Que en toda la entrevista destaca esto como titular. Para mi es el periodista, no es el entrevistado. (E17M)

Uno de los entrevistados comentó también que otra forma de representar a los gitanos en los medios de comunicación que no esté relacionado con crímenes o violencia es por medio del folclore. Una idea que también fue apuntada por Oleaque (2014).

...la gran mayoría de las noticias están relacionadas con estereotipos hacia el Pueblo Gitano o noticias muy folclóricas relacionadas con el cante, con la música, que son las visiones que tiene la sociedad hacia el Pueblo Gitano, o gran parte de la sociedad pues ve al gitano como una persona peligrosa y por otro lado ven a los gitanos también como una persona muy folclórica, que canta, que baila, y ya está. Y eso una gran parte de las noticias pues hacen referencia a esa visión estereotipada llena de prejuicios que tiene la sociedad y lo que hacen esas noticias es reforzar esta imagen. (E8H) 
Aunque la mayor parte de los comentarios recibidos son críticas, también conviene aclarar que dos de los entrevistados creen que se ha mejorado de algún modo la cobertura que los medios de comunicación hacen sobre los gitanos. Sin embargo, destacan que ello se debe a los esfuerzos del Pueblo Gitano en reivindicar los cambios y al aumento del activismo en la comunidad, lo que hace que las noticias sean más positivas. Creemos importante mencionar también que casi la mitad de nuestra muestra ha sido entrevistada al menos una vez por medios de comunicación. En general, la mayoría de las entrevistas estaban relacionadas con el entorno del asociacionismo. Pero lo que nos interesa destacar aquí es, sobre todo, una queja que apareció en varios encuentros, el carácter repetitivo de las preguntas, lo que revela la deficiencia de las rutinas periodísticas.

...luego lo mismo, ¿por qué estudias?, ¿cómo es que has estudiado y no has tenido fracaso escolar?, ¿cómo ha sido tu proceso de ir a la universidad?, ¿cómo te has sentido en la universidad?, sabes, o sobre tu trabajo, es como muy repetitivo todo. (E12M)

He hecho bastantes entrevistas para medios de comunicación y muchas de ellas no me han gustado porque te preguntan unas cosas que luego ellos ponen en la forma que ellos quieren y es real que tú has dicho eso, pero no con esa intención, ni en ese contexto. Y básicamente siempre de lo mismo, a veces cansa, es siempre y los gitanos y no sé, tonterías que no llevan a nada. ... La última vez que hice una, no me gustó mucho, lo leí luego en el periódico y no me gustó nada, nada, nada, nada. Aparte lo hicieron por teléfono, me hicieron dos preguntas y las preguntas eran como una pregunta cerrada, no era sí o no entonces y yo decía sí y ella ponía E4H dijo esto esto y yo dije sólo sí. (E4H)

...normalmente siempre toca alguna pregunta que suele ser un poco morbosa. Por ejemplo, es normal que siempre te pregunten el pañuelo, qué es el pañuelo del Pueblo Gitano o te preguntan cosas que no representan al Pueblo Gitano que sí a lo mejor haya personas del Pueblo Gitano que sí que hacen esta tradición, pero que no representa a todos y siempre hacen preguntas de este estilo que 
suele ser más morbosa y yo creo que suele vender mucho, que suele vender hacia el público en general. Entonces creo que dependiendo del canal de televisión o dependiendo también de la entrevistadora las preguntas pueden ser mejor o peor, pero digo que normalmente alguna pregunta morbosa suele aparecer. $(\mathrm{E} 8 \mathrm{H})$

Recuerdo también anecdóticamente una situación en la que me hicieron una entrevista casi de una hora para un ... especial, exacto sobre mujeres, me entrevistaban, me hicieron una entrevista de una hora y al final salía mi foto y debajo cuatro líneas y las cuatro líneas decían: está soltera, no le importaría casarse con un no gitano y son pocos de familia. Me quedé, bueno esto qué es, que me están poniendo en una página de contactos en vez de un especial de mujer, de mujeres del siglo XX, XXI. iQué horror! ... Y luego, últimamente también me hicieron otra entrevista para El Periódico y, la verdad, que muy contenta con la periodista, fue muy justa. (E17M)

Otra cuestión apuntada es la necesaria adecuación de los formatos a la complejidad de los temas tratados en las entrevistas, ya que el desconocimiento hacia el Pueblo Gitano hace que sea necesario contextualizar las respuestas o, incluso, hacer un breve recorrido histórico para explicar temas que afectan a la población gitana en la actualidad.

...hace poco me entrevistaron para una revista en inglés. La entrevista estuvo muy bien porque, bueno, como es escrito pues, te permite hablar, ir a fondo y perder tiempo entrevistando, por ejemplo. En la radio no hay tiempo para entrevistar, dan muy directas las preguntas y a veces es difícil explicar cosas muy directamente, necesitas muchos puntos de apoyo, la opinión y tal, y en la radio se pierde, estando en la radio me sentí como que ya había perdido un poco la entrevista, había volado. (E16H) 


\section{CONCLUSIONES}

En cuanto a las reflexiones teóricas referentes a la audiencia, vemos que, en lo referente a su carácter activo o pasivo frente a los contenidos informativos sobre la población gitana, hay una postura muy crítica por parte de nuestros entrevistados en cuanto a lo que se está produciendo. Ello evidencia la agencia de este público en el proceso de interpretar y contraponerse discursivamente a estos contenidos y a la forma como ellos son generados. Resaltamos aquí la importancia de las asociaciones gitanas en crear ambientes de debate sobre la representación de esta comunidad en los medios de comunicación españoles. Ello se debe no sólo a las redes de intercambio de mensajes entre sus funcionarios, como también el alcance que estos temas va ganando entre los usuarios y participantes de los servicios y actividades de estas entidades.

Las entrevistas nos muestran que, en el caso de la población gitana en España, se confirman los debates teóricos sobre la ausencia de los grupos minoritarios en los medios, por un lado, y su presencia a través de estereotipos negativos, por otro. En este último caso, la muestra ha destacado las referencias constantes a crímenes y delitos en las noticias relacionadas a la población gitana. Al criticar la identificación étnica en este tipo de material, la muestra nos hace cuestionar hasta cuándo los manuales, recomendaciones y códigos deontológicos serán ignorados por los profesionales y órganos responsables por garantizar los derechos de la ciudadanía, ya que la falta de una representación real de la complejidad de la cultura de las minorías y de un espacio permanente de difusión de sus voces profundiza su exclusión de los procesos comunicativos en cuanto ciudadanos.

Las experiencias como entrevistados en diferentes medios de comunicación nos indican también la necesidad de formación de los profesionales en lo referente a la adaptación de formatos y contenidos a temas que históricamente no tienen una cobertura adecuada en los medios y también en lo referente al acceso a la historia y cultura de grupos minoritarios. En el caso específico del Pueblo Gitano, estas reflexiones se enmarcan en un momento de evaluación y transición de las políticas públicas europeas relacionadas a las estrategias nacionales para su integración en todos los estados 
miembros de la Unión Europea. Los resultados de 10 años de trabajo nos mostrarán en qué se han avanzado, asimismo nos queda claro que las próximas estrategias no pueden dejar de incluir los retos de la representación y los medios de comunicación ya que el campo simbólico interfiere directamente en el imaginario dominante sobre la población gitana y, consecuentemente, en el acceso a sus derechos básicos.

\section{REFERENCIAS BIBLIOGRÁFICAS}

Barros, A., y Duarte, J. (Org.) (2008). Métodos e técnicas de pesquisa em comunicação. São Paulo: Atlas.

Cogo, D., Gutiérrez, M., y Huertas, A. (2008). Migraciones transnacionales y medios de comunicación - Relatos desde Barcelona y Porto Alegre.Catarata: Madrid.

De Certeau, M. (1995). A cultura no plural. Campinas, SP: Papirus, 1995.

Huertas, A. (2013). La audiencia investigada. Gedisa Editorial: Barcelona, 2013.

Huertas, A. (2018). El estudio de las minorías como audiencia. El caso de la población migrante. Anuario Electrónico de Estudios en Comunicación Social "Disertaciones", 11(1), 40-55, 2018. Recuperado de https://revistas.urosario.edu.co/xml/5115/511554775004/html/index.html

Kellner, D. (2001). A cultura da mídia-Estudos culturais: identidade e política entre $o$ moderno e o pós-moderno. Bauru, SP: EDUSC.

Murray, J. H. (2003). Hamlet no Holodeck - o futuro da narrativa no ciberespaço. São Paulo: Itaú Cultural: Unesp.

Oleaque, J. M. (2014). Los gitanos en la prensa española - Variación y reiteración de los planteamientos de los diarios $A B C$, El País y La Vanguardia en la representación de los gitanos como grupo (1981-2010). Tesis Doctoral Universitat de València: Valencia.

Ross, K. (2001). White media, black audience: Diversity and dissonance on British Television. En K. Ross y P. Playdon (Eds.) Black Marks: Minority Ethnic Audiences and Media. Ashgate Publicshing Limited, Hampshire. 
Ross, K., y Playdon, P.(Ed.) (2001). Black Marks: Minority Ethnic Audiences and Media. Ashgate Publicshing Limited, Hampshire, 2001.

Sodré, M. (2002). Antropológica do Espelho: uma teoria da comunicação linear e em rede. Petrópolis, RJ: Vozes.

Tortajada, I. (2009). ¿Qué hay de nuestro aquí? Cómo se perciben en los medios algunas minorías residentes en Cataluña. Zer, 14(26), 59-80.

Tsagarousianou, R. (2001). Ethnic minority media audiences, community and identity: the case of London's South Asian and Greek-Cypriot communities. En K. Ross y P. Playdon (Eds.) Black Marks: Minority Ethnic Audiences and Media. Ashgate Publicshing Limited, Hampshire.

Willem, C. (2010). 'Roots and Routes' - Young people from diverse ethno-cultural backgrounds constructing their identities using digital media. Tesis Doctoral Universitat de Barcelona: Barcelona.

Wolf, M. (1995). Teorias da Comunicação. Editorial Presença, Lisboa, 1987, 1992, 1994, 1995. 